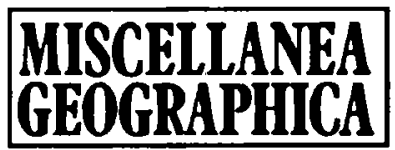

WARSZAWA 1996 VOL. 7

Anna Achmatowicz-Otok, Andrzej Jarosz

\title{
THE ANALYSIS OF THE LAND PRICES IN WARSAW
}

The study reported here ${ }^{1}$ was based upon the data collected by the Land Survey and Economy Department of the Voivodship (provincial) Office in Warsaw. The data refer primarily to 1992 , but also to 1993 . These are the data on prices of 468 individual land plots, including also the type of current use, the date of price fixing and the location information. Prices come from various sources, which can be divided into three main categories: (1) notary prices (of plots for which transactions were concluded, prices were recorded conform to the notarial transaction deeds), (2) real estate agency prices (plots offered for sale through such agencies), and (3) evaluations provided by experts for various purposes, e.g. for the establishment of fees in case of lease or tenure.

Each plot for which a price was determined was treated in the analysis as a point in space of definite coordinates, implying the price of a square metre in exactly this point. The established origin of the coordinate system was the centre of the dome on the Holy Trinity Evangelical-Augsburg church at Małachowski square, corresponding roughly to the very centre of Warsaw.

Given that 468 points were analysed from the area of the town totalling 485 sq.km (one point per 1.04 sq.km on the average) it was deemed adequate to adopt the precision of $0.2 \mathrm{~km}$ along the N-S and W-E axes. This degree of precision seems to be sufficient, considering the fact that the points are in reality distributed irregularly (most densely within some peripheral areas - the family housing quarters).

In order to make possible the comparison of prices expressed in Polish zlotys for 1992 and 1993, i.e. during high inflation period, the prices were converted to US dollars (USD) according to current exchange rates set by the National bank of Poland.

Yet another problem was constituted by the necessity of uniformization of prices obtained from various sources. There are definite differences in the

\footnotetext{
${ }^{1}$ This study is a part of a bigger project undertaken by Andrzej Jarosz under the direction of Anna Achmatowicz-Otok within the Department of Social Geography of the Faculty of Geography and Regional Studies at the University of Warsaw.
} 
setting of prices within the three categories quoted above. The agency prices are the call prices for the items offered for sale and in concluding a transaction, if one actually occurs, they are as a rule corrected downwards. Then, the notary prices are the reflection of the transaction prices, provided that these two are equal, which is often not true, since on many occasions the parties to transaction have an interest in reducing the notarial fees and the sales tax, which are both functions of the official price. Yet other prices are established by the experts. They are namely established for a variety of purposes and with a variety of methods. Thus, in order to have the prices comparable it was necessary to transform them into a unified system. The category of "notary prices" was selected as the basic one, because the majority of data (312, i.e. $67 \%$ of the entire set) were expressed in these prices, and because this category corresponds to the price for which, at least theoretically, one could purchase land in Warsaw in the years 1992/1993.

In the transformation of prices from the categories "agency prices" and "remaining" (or "expert evaluations") to the notary prices the assumptions were made stipulating that the prices of land plots located nearby are similar and that in all the price categories similar factors influence in alike manner price formation (e.g. attractiveness of the area with respect to various features, like distance from downtown Warsaw, water supply system, gas supply etc.). Then, three cross-reference tables were formed (notary/agency, notary/remaining, and agency/remaining) in which distances were calculated between all the respective points. After calculations involving the notion of minimum threshold distance between respective categories and the regression models for the subsets of pairs of plots within this threshold it was decided that sufficient comparability of prices could be secured. Finally, the prices were expressed in USD in terms of notary prices.

The subsequent step consisted in elaboration of the map. For this purpose the software package SURFER Access System ver. 4.15 of Golden Software Inc. was used. The isoline map was traced on the basis of values calculated in the respective grid points. The $32 \mathrm{~km} \times 32 \mathrm{~km}$ area was divided up with the grid of $33 \times 33$ lines distanced by $1 \mathrm{~km}$, which defined the grid points. Calculations of the price values in the grid points were carried out with the method of inverse distance, with the parameters of inverse distance weighting power $=4$, quadrant search $=4$, and 4 nearest points. ${ }^{2}$ The

2 according to the formula $Z_{g}=\frac{\frac{Z_{1}}{D_{1}^{4}}+\frac{Z_{2}}{D_{2}^{4}}+\frac{Z_{3}}{D_{3}^{4}}+\frac{Z_{4}}{D_{4}^{4}}}{\frac{1}{D_{1}^{4}}=\frac{1}{D_{2}^{4}}+\frac{1}{D_{3}^{4}}+\frac{1}{D_{4}^{4}}}$ where:

$Z_{g}$ - value in the grid point,

$Z_{1}, \ldots Z_{4}-$ values in the consecutive closest points around the grid point,

$D_{1}, \ldots D_{4}$ - distances of the consecutive closest points to the grid point. 
parameter values given, the computer program looks around each of the 1089 grid points for the four closest data points (parameter setting) in the four quadrants (parameter) of the circle surrounding the respective grid point. The purpose of this search is to determine the value representing the prices for the area around the grid point, and not in just, say, one location that is close to it. The values of distance from the grid point appear in the fourth power so as to enhance the significance of the data points located the closest, out of all those accounted for.

Spatial differentiation of the land prices in Warsaw is shown in Fig. 1. The maximum prices in the years 1992-1993 attained - in downtown Warsaw -498 USD/1 sq.m. On the map, though, in view of the method applied, the highest values are flattened out. The area featuring the highest prices - enclosed within the isopleth of $200 \mathrm{USD} / \mathrm{sq} . \mathrm{m}$ - is well pronounced. This isopleth defines the strict trade, administrative and office centre, gradually transforming into the classical CBD. A broader central area, which approximately coincides with the quarter of the Downtown Warsaw (Warszawa-Sródmieście), is contained within the isopleth of $150 \mathrm{USD} / \mathrm{sq} . \mathrm{m}$. The urban areas with the housing function and a high share of the trade and service function of the town-wide importance are, in turn, approximately coinciding with the commune of Warsaw-Centre (the isopleths of 50-70 USD/sq.m). Here, also, the two most expensive estates appear - the central part of Żoliborz and Saska Kepa, where the shares taken by the family housing and the prices of more than 70 USD/sq.m are important. An exception, on the other hand, is constituted by an essential part of the quarter of Wola, being largely an industrial area, with the old and worn out or outright derelict buildings located quite near to the proper centre of town, and where now the greatest number of new investment projects of trade and office character is located. It is highly probable that in the future the function of these areas will get transferred towards the ones proper for the strict center of town, the supply of land will decrease and this will entail a sharp increase of prices. The remaining areas of the commune Warsaw-Centre (Warszawa-Centrum) featuring lower prices are the eastern (river-valley bottom) part of Mokotów quarter - the as yet undeveloped area meant in the land use planning for the central urban functions, but with little hope for a quick change of the state of affairs there, and the eastern part of the Praga South (Praga Południe) quarter, with housing function, but low density of service and trade activities essential for town. Outside of the Warsaw-Centre commune high land prices, exceeding 50 , or even $70 \mathrm{USD} / \mathrm{sq} . \mathrm{m}$ are observed in the exclusive suburban family house estates in the communes of Wawer and Wilanów, the large housing estate of Ursynów commune, the mixed family and block-type estate in Bemowo commune, as well as the areas related to the Okęcie airport in Whochy commune. The prices of more than 10-20 USD/sq.m are observed in the suburban estates of family houses, where bigger multistorey building clusters appear 


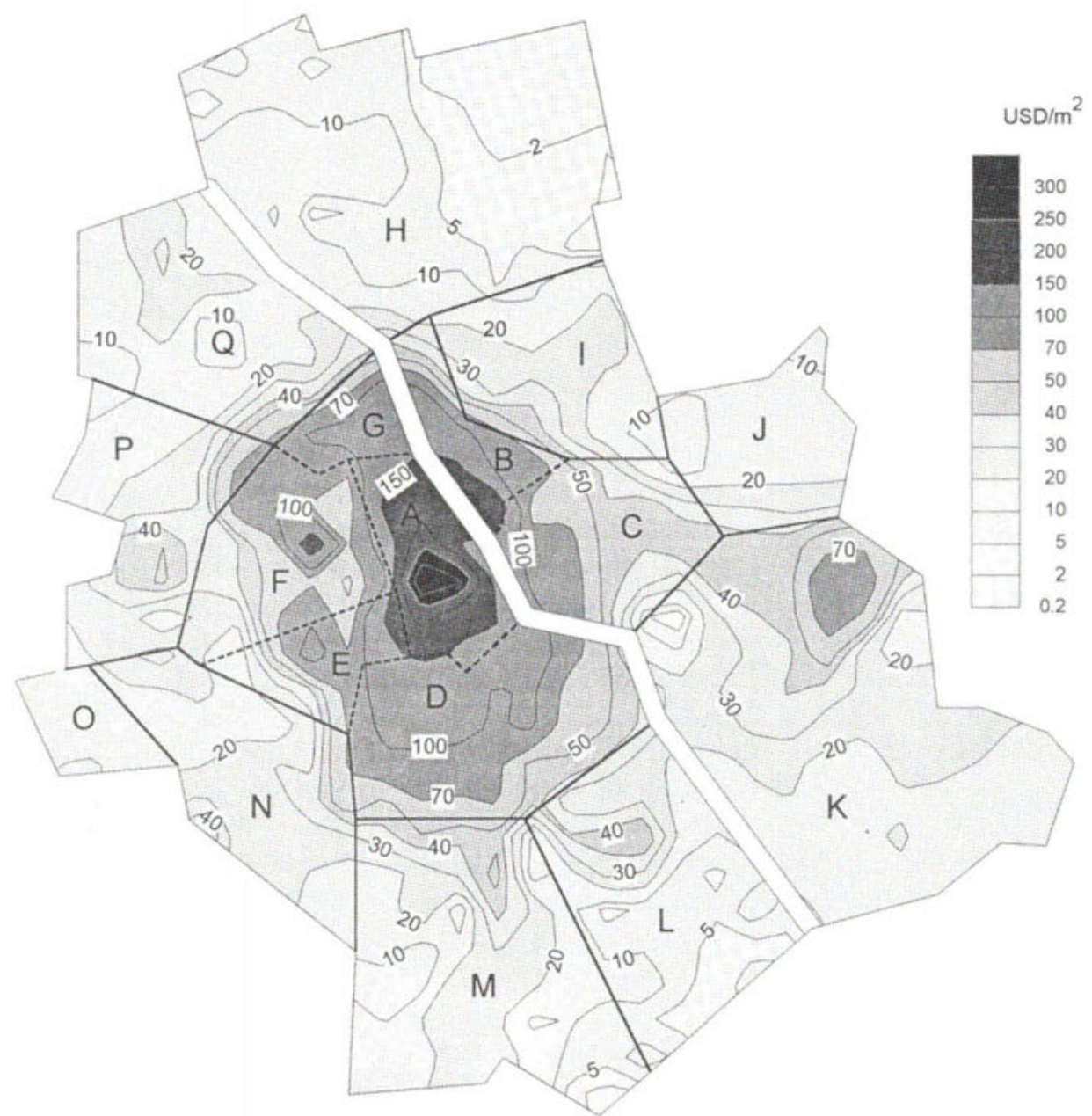

Districts of Warszawa-Centrum Commune'

A. Srodmiescie (CBD)

B. Praga Pónoc

C. Praga Poludnie

D. Mokotow

F. Wola

G. Zoliborz
Other communes of Warsaw:

$$
\begin{aligned}
& \text { H. Bialolekka } \\
& \text { I- Targowek } \\
& \text { J-Rembertow } \\
& \text { K- Wawer } \\
& \text { L- Wilanow } \\
& \text { M- Ursynow } \\
& \text { N. Wlochy } \\
& \text { O- Ursus } \\
& \text { P. Bemowo } \\
& \text { Q- Bielany }
\end{aligned}
$$

Fig. 1. Prices of land in Warsaw

as well. The lowest prices, below $10 \mathrm{USD} / \mathrm{sq} . \mathrm{m}$, are characteristic for the agricultural land, with exception of Bielany commune, where the lowered prices in the centre of the commune are connected with the neighbourhood of the environmentally disruptive Lucchini Steelworks. 
Summing up we can state that the land prices in Warsaw are quite closely connected with the existing state of development. High differentiation of prices, from $0.10 \mathrm{USD} / \mathrm{sq} . \mathrm{m}$ to $500 \mathrm{USD} / \mathrm{sq} . \mathrm{m}$, and even much more in some individual transactions, results from the fact that within the administrative boundaries of the town there are the central areas with very low supply of land plots (worsened by the still not clarified ownership status of a large part of real estate in the commune of Warsaw-Centre), along with the agricultural land, quite distinct from the other areas of the agglomeration.

\section{THE INFLUENCE OF THE DISTANCE FROM THE CENTRE ON LAND PRICES}

In the von Thünen's model ${ }^{3}$ the function of the land rent along distance has the form of monotonically decreasing straight line. In case of variable land use the respective functions will be characterized by different slope angles, as also in the case of varying transport cost $-\tau$. If we adopt the assumption of maximization of the land rent (which is true in conditions of market economy), then the function of the land rent as depending upon distance under variable land use will always take the form of a decreasing concave curve.

When we transfer this model to urban conditions then individual factors change their meaning. Transport costs no longer depend primarily upon energy spent on translocating products from location of their manufacture to the market, since both weights and distances are much smaller here, but, on the other hand, greater importance is gained by such factors as time of transport and closeness to the market (marketing and prestige aspects). Production per unit of land does no longer mean here agricultural productivity of land, but rather production of commodities, and even more often of services, which can be realized per unit of surface. In spite of these differences the model preserves its validity, because the effect of action of the transformed factors is analogous.

Application of the von Thünen's model to the analysis of the prices on land plots in Warsaw was done under the assumption of a strict dependence

\footnotetext{
${ }^{3} \rho=p x-c-\tau x r$

where:

$\rho$ - land rent on the supply side,

p - price of product on the sole central market,

$x$ - quantity of product per unit of land,

$c$ - local production cost,

$\tau$ - cost of transport per unit of product and distance,

$r$ - distance to the market.
} 
between the land rent and the land price (e.g. a part of data came from the evaluation of land for purposes of establishment of life tenure fees). Analysis was performed as to the dependence of the land prices in USD on the distance from the point featuring the highest prices (translocated to the South from the origin of the coordinate system). The exponential regression function was used for this purpose, since it corresponded to the general requirements of the model and explained the best the variability studied $\left(R^{2}=0.5012\right.$ at the confidence level of $\alpha=0.001$ ). The regression curve (Fig. 2) is represented with a straight line in view of the semi-logarithmic scale used, due to the possibility of simultaneous presentation of prices in particular points.

The model presented explains quite a lot, namely $50 \%$, of variability, but, as can be concluded from it, the prices are influenced also by the factors here not accounted for, because space (morphology, transport network etc.) in Warsaw is not uniform.

Fig. 3. presents the same regression curve, shown in the linear scale, and applied in the von Thünen's model, with the assumption of the continuous change of model parameters. Three tangent lines to the regression curve are also shown in this figure, characterizing various land uses:

A - maximum slope (the greatest $\tau$ ), tangent in point 0 ;

B - somewhat less steep slope, tangent in the point $4.5 \mathrm{~km}$;

$\mathrm{C}$ - minimum slope, tangent in the point $11.5 \mathrm{~km}$.

These three straight lines symbolize various uses of land, from the most intensive one, but sensitive to the distance from the centre, to the little intensive and little sensitive to the distance from the centre.

At the point of intersection of the lines $A$ with $B$ and $B$ with $C$ the boundaries were defined of the three functional zones of the town, resulting from the assumption of maximization of prices.

First zone - with domination of the central functions (trade, administrative and office centres). They are located within the radius of approximately $2 \mathrm{~km}$ from the central point and are characterized by the important decrease of prices with distance.

Second zone - shows the reach of the block-type housing with a share of the service function (prices less sensitive, but dependent on the accessibility of the trade and service facilities, as well as municipal transport, which worsen generally along the distance from the centre). This zone stretches up to some $7 \mathrm{~km}$ from the central point and encompasses the commune of Warsaw-Centre.

Third zone - peripheral. Here the family house estates are located, but also industrial areas as well as agricultural land, and distances have fairly less of significance.

Quite an important agreement of this, after all, relatively simple model with the situation in Warsaw is indicative for the existence and role of the market rules in the urban land economy. It should be remembered that on 


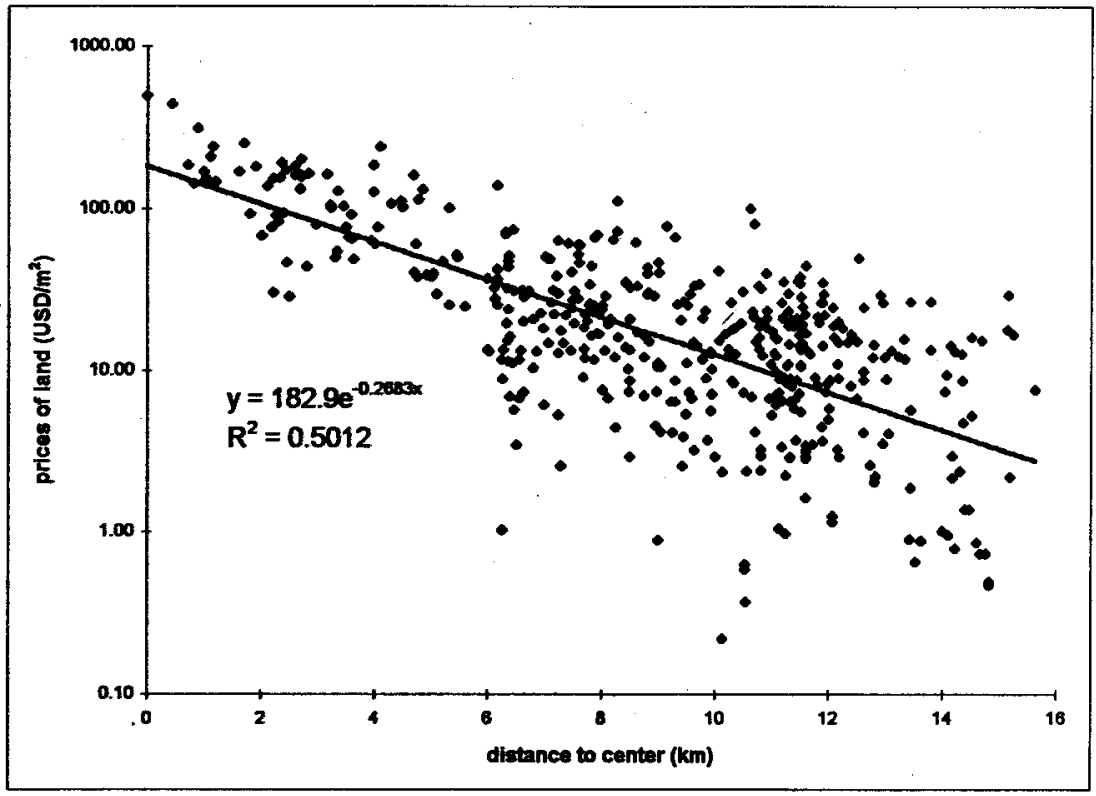

Fig. 2

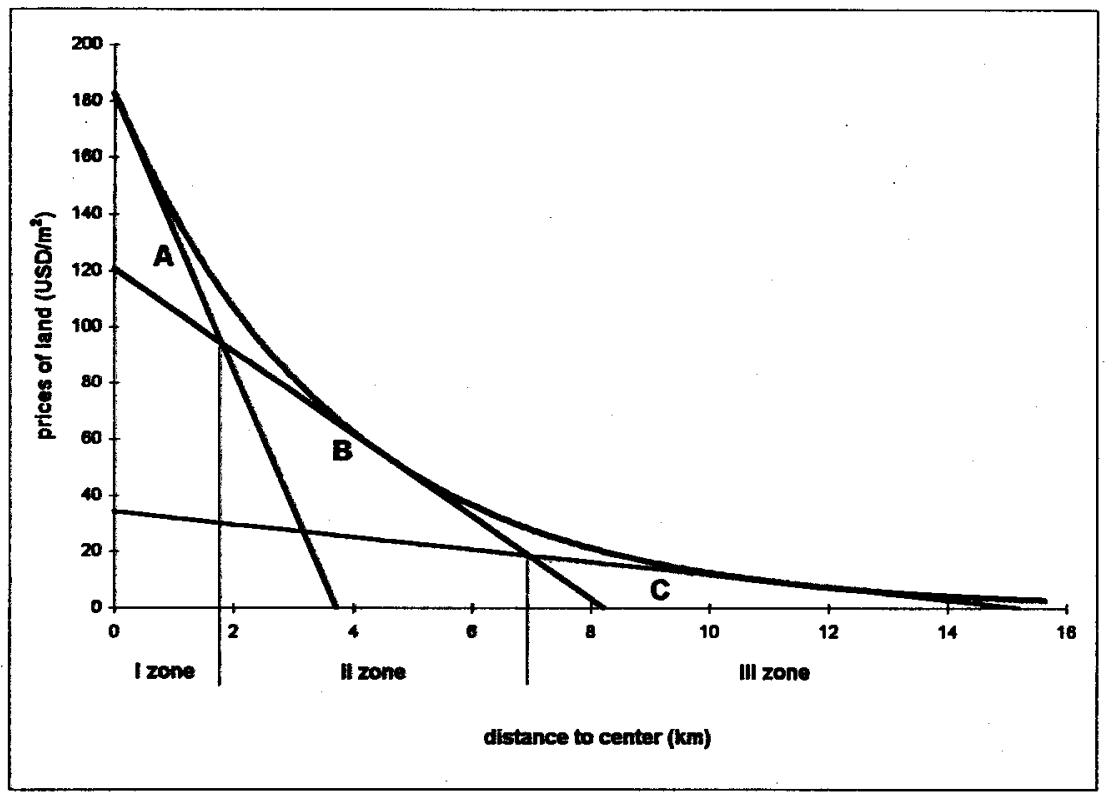

Fig. 3 
the basis of the decree of 1945 all the land of pre-war Warsaw (corresponding roughly to the present commune of Warsaw-Centre) was appropriated by the commune and for almost 50 years almost all of the land within this area has not been subject to the market rules. The areas of the communes surrounding now Warsaw-Centre are in their majority private, and they have been the subject of market operations all the time. It is within these areas that the local "islands of higher prices" have appeared (Fig. 1), surrounding the Centre with a ring. Appearance of higher prices of land is observed in the peripheral areas having particularly attractive natural environment (e.g. Anin and Międzylesie in Wawer commune), and the vicinity of historical monuments and parks (e.g. Wilanów). These areas had most often belonged to previously independent resort localities and have been gradually incorporated in the greater Warsaw after 1945, and so the respective land avoided being made communal property on the basis of the decree mentioned. 